Lexis Vol. XLIV (1) 2020: 175-203

\title{
Abraham Valdelomar y el topos de la "ciudad muerta": diálogo e identidad
}

\author{
Giovanna Arias Carbone \\ Universidad Complutense de Madrid
}

\section{RESUMEN}

Las dos novelas cortas de Abraham Valdelomar, La ciudad muerta y La ciudad de los tísicos, han sido relegadas por la crítica tradicional, pese a proponer una revolución ideológica y estética. Sobre la base del difundido topos literario de la "ciudad muerta", en estos textos se simboliza el fin de la ciudad colonial. Una lectura comparativa permite distinguir dos formas de procesar la muerte del pasado reciente nacional: una cristiana, siniestra y que intimida desde sus ruinas (en La ciudad muerta); y una andina, benévola y representada desde el apacible remanso que habitan los tuberculosos, como una suerte de purgatorio (en La ciudad de los tísicos). Dentro del ineludible debate político sobre la identidad y la literatura nacionales, todavía vigente a inicios del siglo $\mathrm{XX}$, la intención última del autor sería crear el espacio del discurso híbrido en el relato modernista, donde las muertes conviven y un nuevo estilo literario emerge de la confluencia entre las tradiciones antes que de la exaltación de un tiempo en "ruinas".

Palabras clave: Abraham Valdelomar, La ciudad muerta, La ciudad de los tísicos, novela modernista peruana, discursos nacionalistas 
Abraham Valdelomar and the Topos of the "Dead City": Dialogue and Identity

\section{ABstract}

The two short novels by Abraham Valdelomar, La ciudad muerta and La cindad de los tísicos, have been neglected by traditional critics, despite the fact that they both propose an ideological and aesthetic revolution. Based on the well-known literary topos of the "dead city", these works represent the end of the colonial city. A comparative analysis allows to examine how they depict two ways of dealing with the death of the recent national past: a Christian, sinister and intimidating discourse shaped by its ruins (in La ciudad muerta); and an Andean, benevolent depiction of the past, as embodied by the tuberculosis patients who inhabit a purgatory alike village (in La ciudad de los tísicos). In the context of an intense political debate on national identity and national literature, the author aims to develop a hybrid discourse within the modernist narrative, where different concepts of death coexist and a new literary art emerges from the confluence rather than the celebration of a time "in ruins".

Keywords: Abraham Valdelomar, La ciudad muerta, La cindad de los tísicos, Peruvian Modernist Novel, Nationalist Discourses

\section{Introducción}

La crítica en torno a la voluminosa obra de Abraham Valdelomar ha tendido a privilegiar aquella parte que explícitamente aporta mayores tintes locales a la tradición literaria peruana, como es el caso de los denominados "cuentos criollos". Este fenómeno de recepción se sitúa en un contexto en que las tendencias indianistas o indigenistas cobraban mayor protagonismo, y seguía abierto el proyecto de crear un canon nacional, iniciado por intelectuales como Manuel González Prada, Ricardo Palma o José Santos Chocano. La consecuencia radica en que buena parte de la narrativa del autor iqueño haya sido leída como mero ensayo dentro de un proceso de maduración estilística, por medio de la imitación "fallida" de modelos europeos. Así, su adaptación del popular topos literario de la "ciudad muerta" pasó a la historia como una extravagancia 
pueril y un homenaje hacia uno de sus autores predilectos, Gabriele D’Annunzio, quien en 1896 escribe la tragedia Città morta. Sin embargo, basta mirar por encima la obra completa de nuestro autor para confirmar que el tema de la muerte es el gran "leitmotiv de sus fantasías" (Castro y Oyanguren 2003: 23) y el delicado hilo conductor de una necesaria experimentación formal e ideológica a principios del siglo XX. Aparece en sus "cuentos yanquis", de manera lúdica y libre de velo trágico; en sus "cuentos incaicos", ligado a la mitología andina y a la concepción de la muerte como continuidad; y, en sus "cuentos criollos", como interrupción de la inocencia y la plácida vida aldeana ${ }^{1}$. Entre esa variedad de enfoques, la adaptación del popular topos representa otra arista para la exploración de una propuesta modernizadora multiforme.

En el presente trabajo, analizaremos los alcances del topos dentro de las dos novelas cortas, La ciudad muerta. Por qué no me casé con Francinette (1911) y La ciudad de los tísicos. La correspondencia de Abel Rossel (1911). Retomando el interés reivindicatorio de María Elena Martínez-Acacio (2007) y Susana Santos (2015), quienes otorgan a las obras un carácter complejo, interrelacionado y desde donde se expone una preocupación por lo nacional, veremos cómo Valdelomar se vale de un modelo finisecular para proponer, como buen modernista, una versión renovada en combinación con sus propias tradiciones locales ${ }^{2}$. Para ello, exploraremos, primero, los usos tradicionales del topos en determinados contextos y acla-

\footnotetext{
Sigo la categorización de la narrativa hecha por Ricardo Silva Santisteban en su edición en las Obras completas y adoptada por Carlos Garayar en los Cuentos reunidos (2014). Si bien, como propondré más adelante, no es mi deseo perpetuar las viejas clasificaciones de la obra de Valdelomar, apelar al orden establecido de los cuentos, en este caso, permite demostrar que la muerte es el tema por excelencia en todas sus "etapas".

2 Martínez-Acacio, como parte de su relectura de la narrativa de Valdelomar en vinculación con el proceso de formación de la literatura nacional, plantea que ambas novelas ofrecen una imagen de Lima en respuesta al veloz desarrollo de las ciudades latinoamericanas y los conflictos asociados a una modernización acelerada e inequitativa. Por su lado, Susana Santos, desde una revisión diacrónica de la cartografía limeña, representada o imaginada a través de la ficción, otorga a las novelas un carácter utópico y dialéctico, inventor de una nueva forma urbana que denuncia la persistencia de una organización señorial y admite la modernidad.
} 
raremos los elementos que recoge en sus versiones. Luego, nos aproximaremos al tema de la muerte de la ciudad colonial desde dos enfoques: uno cristiano, plasmado, sobre todo, en La ciudad muerta, y uno andino, en La ciudad de los tísicos, aunque con evidentes puntos de contacto entre ellos. Finalmente, precisaremos cómo ambas novelas invitan a superar la desaparición de la ciudad colonial, desde el espacio de la creación literaria y por medio de la convergencia de las múltiples influencias culturales que deberían conformar el "verdadero" arte local.

2. La ciudad muerta como metáfora de la decadencia moderna

Para comprender mejor sus implicaciones ideológicas en determinados contextos históricos y, en particular, en los tiempos del autor peruano, es necesario explorar brevemente los orígenes y evolución del topos. Desde su fijación en 1892, con la publicación de Brujas la muerta de Georges Rodenbach, su propagación por Europa e Hispanoamérica es veloz. Sin embargo, sus antecedentes se remontan a las floridas descripciones arqueológicas de mediados del siglo XIX, cuando se intentaba describir la majestuosidad de las viejas ciudades transformadas en museos, fuese que estuviesen habitados o no. Ahora bien, el concepto se empleaba de manera poco rigurosa -algo que, como veremos, persistió en la literatura y en la misma obra de Valdelomar-, pues servía también para definir espacios propicios para la vida contemplativa, donde sencillamente reinaran la calma y la nostalgia ${ }^{3}$ (García Pérez 2008: 121-122).

La aplicación como proyección simbólica del mundo interior o analogía de los sentimientos, que afianza Rodenbach, privilegia el sentido connotativo antes que el denotativo, ya que la ciudad no precisa estar literalmente muerta y enterrada: es suficiente que uno solo de sus habitantes la transite de manera casi fantasmal y que el lugar posea un aura propicia para la desconexión entre el hombre y

\footnotetext{
Algunos usos tempranos del sintagma se aprecian en La dama de las camelias (1848), de Alexandre Dumas hijo; y en la poesía de Gustavo Adolfo Bécquer, cuando describe a Toledo en 1870 (García Pérez 2008: 122).
} 
el espacio físico ${ }^{4}$. De esa manera, el topos remite, en muchos casos, a orbes moribundas antes que muertas, que, como si se tratasen de otro personaje, son poseedoras de alma, de recuerdos y hasta de una nostalgia intrínseca en casi todo elemento que las configura (García Pérez 2008: 122-123). Se produce, así, un efecto de metonimia entre el gran cuadro de muerte y desolación, y su proyección en el alma moribunda del narrador.

Si bien Rodenbach populariza la visión romántica de la ciudad muerta (o moribunda), otros autores optarían por la muerte más tangible de una ciudad desaparecida. Este es el caso del poeta Albert Samain —citado por Valdelomar en La ciudad muerta-, quien, en su soneto "Au jardin de l'infante" (1893), retrata un paisaje majestuoso, semienterrado en la arena y vacío, como Pompeya, ciudad muerta por antonomasia. En la visión de Samain, el espacio actúa menos como metáfora del alma del “yo poético" y predomina su capacidad para activar la imaginación desde las ruinas (García Pérez 2008: 127-128) $)^{5}$. Notamos que, aunque coexistan dos versiones de la muerte de un espacio, estas pueden surgir de sentimientos similares y, en ese sentido, son capaces de fraguarse en una misma obra. Valdelomar vería, precisamente, el potencial de esta complementariedad para representar la decadencia postcolonial en sus novelas.

La vertiginosa propagación del topos en sus dos versiones se debe a un contexto propicio para desatar sentimientos de nostalgia entre los espíritus más sensibles: el industrialismo del siglo XIX. Ocurre que, según explica Miguel Ángel Lozano, “el mundo industrial y el pragmatismo inherente a la mentalidad positiva van dejando

4 En la novela, Hugues, el protagonista, decide trasladarse a Viena tras la muerte de su esposa, luego de concluir que Brujas es la ciudad que mejor sintoniza con su estado melancólico. Se hallaba atraído por "buscar analogías de su duelo en los canales solitarios y los barrios eclesiásticos” (Rodenbach 2011: 10).

5 Cabe aclarar que la "ciudad muerta" del simbolismo no es completamente equivalente al topos de las “ruinas”, principalmente desarrollado en la poesía del Renacimiento al Romanticismo. Como apunta David Friedman, de los dos usos de la poesía de las ruinas en la tradición francesa, uno vinculado a la fragilidad de la vida y otro a la asimilación entre la ciudad y la naturaleza, las ruinas del simbolismo belga de la ciudad muerta se acercan más al primero: representan la degradación del alma humana por una enfermedad espiritual que se proyecta a un mundo sin tiempo (1990: 7-16). 
fuera de circulación valores e ideales; pero también ambientes y paisajes. Las ciudades iban perdiendo -para algunos- su encanto íntimo, una identidad que procedía de su tradicional organización social y de su idiosincrasia artística y cultural". Es la resistencia de lo estético frente a lo utilitario (2000: 18). Sin embargo, el artista no apela al modelo cual "culturalista" que anhela las costumbres tradicionales de un paraíso perdido buscando reinstaurarlas; en realidad, se recrea en un presente paralelo, desde donde asume que el pasado está perdido y la actualidad es hostil, algo que asimila muy bien la “Generación del 98” en España ${ }^{6}$. Desde esta aplicación tradicional, el tiempo análogo reúne lo mejor del pasado y acaba en sí mismo, sin una salida al futuro, como el tiempo de la deleitosa agonía, que no es ni el de la vida ni el de la muerte (Lozano 2000: 19).

\section{Tiempos modernos sobre ruinas coloniales}

Al explorar la muerte de la ciudad colonial en sus dos novelas, Valdelomar es filosóficamente afín a los nostálgicos intelectuales europeos que lo preceden. Se muestra igual de crítico con el presente del país, que exagera la modernización urbana y solo rescata viejos valores para su instrumentalización política. Desde antes del gobierno de Augusto. B. Leguía, aunque con especial énfasis en aquel periodo ${ }^{7}$, se empieza a gestar en el Perú una nueva sensibilidad

\footnotetext{
6 España dejó notables testimonios de la búsqueda de valores tradicionales en medio de la acelerada expansión urbana luego de la Primera Guerra Mundial. Se despiertan sentimientos del artista por aferrarse a un espacio agonizante, sin pretender "reflejar lo típico y folklórico, lo regional”, sino buscando indagar en "algo más sustancial e íntimo, más perenne y eterno” (Cansinos-Assens 1925: 151); así, aparecen esas dos Españas que corren análogamente y conmueven a los miembros de la "Generación del 98". Por ejemplo, José Martínez “Azorín” emplea el topos de la “ciudad muerta” en la escritura de La voluntad.

7 Desde su primer gobierno (1908-1912), Leguía recurrió al gasto público mediante una política de endeudamiento exterior para modernizar la ciudad. Además, se incrementaban las exportaciones al mercado norteamericano, con lo cual la minería cobraba gran importancia y la agricultura decaía. La consecuencia fue un desempleo generalizado y un sentimiento de disconformidad ciudadana. Esta reestructuración ocurre dentro del periodo que Jorge Basadre (1968) denominó como "República Aristocrática” (18951919), para enfatizar la desigualdad casi neocolonial que se vivía en el país.
} 
en respuesta al crecimiento urbano, que acaba por liquidar, sobre todo en el plano estético, a la ciudad virreinal e impulsa un ritmo de vida frenético ${ }^{8}$. Los artistas responden buscando una suerte de “collage" nacionalista desde la estimulación sentimental y emotiva (McEvoy 1999: 251), que Valdelomar llevaría hasta el extremo de la teatralidad, en su "búsqueda de una identidad como escritor y un público para su obra” (McEvoy 1999: 270).

Dado que los procesos históricos son particulares, la de Valdelomar no deja de ser una aplicación sui generis del topos. El escritor toma un impulso distinto del de sus predecesores europeos, quizá menos nostálgico, en su empresa por actualizar el pasado nacional y frenar la vorágine modernizadora. Para comprenderlo mejor, situémonos en su medio literario. Nos hallamos, por simplificar un panorama bastante complejo, frente a dos formas principales de procesamiento del pasado en la temprana nación peruana, que se desdoblan, a su vez, en dos vertientes literarias: la tradición criollo-hispánica, colonial y hegemónica, que tenía por representante a José de la Riva Agüero; y otra de resistencia, encabezada por Manuel González Prada y, seguida, por José Carlos Mariátegui. Según precisaba Antonio Cornejo Polar, la primera "propone una interpretación cerradamente hispanista de la tradición literaria peruana” (1989: 74); mientras que la segunda adoptó la visión anti oligárquica de la burguesía modernizante y el cuestionamiento al pasado (1989: 94-95). En aquel medio fraccionado, un intelectual rebelde y trasgresor como Valdelomar irá tras una estética disímil, capaz de recoger las incongruencias y sincretismos ideológicos del pasado reciente y remoto, con miras a un proyecto más integrador. El topos de la "ciudad muerta" será un molde modernista en el que verter la difícil mezcla.

\footnotetext{
8 A este contexto se suma el sentimiento derrotista que dejó la Guerra del Pacífico (1879-1883), que evidenció entre los jóvenes intelectuales de finales del siglo XIX que los viejos proyectos de patria y sensibilidades románticas habían caducado. Valdelomar declara, en su discurso "Nuestra lucha", que aquella derrota marcó el inicio de "la verdadera decadencia del Perú” y que el principal culpable fue el “desgobierno” (2001, IV: 468).
} 
El tiempo de la ciudad muerta alimenta su creatividad, pero desde una consciencia de la caducidad y de la necesidad de bifurcar el presente a través del tiempo paralelo de la literatura — propuesta que intentará plasmar con mayor contundencia en proyectos como Colónida, según veremos más adelante-. El concepto de "ciudad muerta" es útil a este fin creativo porque, como sostiene Lozano, "viene a constituir un ideal refugio contra la vida [y es] el ámbito adecuado para preservar, potenciar y dar nueva dimensión al sentimiento de la melancolía" (2000: 18) [El énfasis es nuestro]. El propósito de Valdelomar dista, en esa medida, de los impulsos de los decadentistas europeos por proyectar su subjetividad nostálgica en la ciudad moderna. La razón es que, sencillamente, no existe un pasado que pueda ser rememorado o recuperado dentro de un marco literario, sino las tradiciones de una nación en formación.

Tampoco se trata, como postulaban los tradicionalistas románticos o los costumbristas peruanos, de seleccionar fragmentos de la historia andina y virreinal útiles a propuestas políticas nacionalistas modernizadoras. Valdelomar buscará la renovación del pasado, virreinal e incaico, desde la recolección de múltiples fragmentos, como los bloques dispersos para la creación (y recreación, tantas veces haga falta) de un nuevo producto literario, capaz de forjar una sensibilidad actualizada. Esta motivación quedó resumida en uno de sus discursos sobre la literatura nacional: "Es necesario, pues, crear un nuevo arte, tan sincero como el antiguo, pero más en armonía con el sentir moderno. Expresar espontáneamente las ideas, liberarse del prejuicio académico y el yugo clásico; ser libres, veloces y concisos" (2001, IV: 225) [El énfasis es nuestro].

\section{La ciudad colonial muere dos veces}

En medio de su ambiciosa exploración de un arte diferente, Valdelomar recogerá elementos asociados a los dos formatos de ciudad muerta: la enterrada, como las ruinas coloniales que coexisten con el puerto habitado en La ciudad muerta; y la moribunda, como proyección del cuerpo enfermo de los tuberculosos de La cindad 
de los tísicos. Experimentará con el topos, asimismo, en crónicas de viajes. Por ejemplo, en la crónica de su visita a Pompeya, de 1914, sigue ensalzando elementos fijados unos pocos años antes en las novelas y nos ofrece algunas claves de lectura sobre su apreciación del pasado, que iremos desenmarañando en las siguientes páginas. Primero, valora lo pretérito por su efecto, no por sí mismo: "Ignoro el tiempo. Las cosas solo valen por la sensación que dejan”. Luego, contempla una visión positiva de la muerte: "La muerte estaba allí, pero no era hostil". Por último, otorga a la enfermedad la cualidad de agudizar los sentidos y de elevar el espíritu del enfermo: "Hay cosas que solo deben verse después de una enfermedad grave. Jamás el espíritu es tan sutil como después de una fiebre" (2001, I: 349).

La primera novela configurada bajo el topos es La cindad muerta, publicada por partes en la Ilustración Peruana entre abril y mayo de 1911. Valdelomar ensaya una prosa estilizada y cargada de referencias, que recuerda a las evocaciones renacentistas de D’Annunzio. Luis Alberto Sánchez hizo notar su poco aprecio hacia la obra al considerarla producto de una "iconmovedora puerilidad!" (1987: 76). Sin embargo, y tomando distancia de las duras críticas a su estilo preciosista, la novela recoge un sentimiento compartido por otros autores de la época, como Raymundo Morales, acerca de la necesidad de salvaguardar los vestigios de los tiempos virreinales, aunque con un carácter transformador. Está escrita a modo de correspondencia y narra, desde la mirada temporalmente distante - como casi todo relato modernista-, la convivencia de dos ciudades: la viva, "C", donde habita la población de un puerto activo, y la colonial, de la que solo se conservan las ruinas y un misterioso subterráneo que atrae a curiosos viajeros?.

\footnotetext{
9 La crítica suele ver en "C" a la ciudad portuaria del Callao; y en la "ciudad colonial" a Lima, que a principios del siglo XX seguía presumiendo de haber sido uno de los principales virreinatos de España. En todo caso, Valdelomar optó por no nombrar a sus ciudades, con lo cual se percibe una intención anti centralista, es decir, un deseo de plasmar en sus ciudades inventadas la concentración de un imaginario que no se limita a la capital y su puerto. Esta intención también se extiende a La ciudad de los tísicos.
} 
Por su lado, La ciudad de los tísicos, publicada por entregas en la revista Variedades, entre abril y septiembre de 1911, tuvo una recepción un poco menos agresiva por parte de la crítica, aunque nuevamente Luis Alberto Sánchez no le otorgara demasiado crédito al llamarla "relato convencional y de falsa decadencia" (1987: 74). Escrita también a modo de correspondencias en su mayor parte, toma impulso de la visión romántica de la tuberculosis pulmonar como potenciador de la creatividad artística. Como explica Susan Sontag, para el imaginario decimonónico, la enfermedad elevaba el intelecto, con sus rachas de euforia; embellecía el cuerpo, a través del contraste entre la palidez y el rubor de la fiebre tísica; e incrementaba el apetito y el deseo sexual (2003: 24-25) ${ }^{10}$. Es decir, el tuberculoso se perfilaba como un ser vital y animado por el sentimiento erótico, pese a su sentencia de muerte. Ahora bien, aquel héroe tipificado cobraría un valor particular en su contexto latinoamericano, donde canaliza la polémica sobre "las maneras de imaginar y legitimar la especificidad de la práctica artística en el contexto de la modernización acelerada” (Nouzeilles 1998: 295-296). Así se deja ver en la novela del peruano, donde la estética del pasado y la muerte son temas que se entremezclan por medio de evocaciones coloniales en la quinta del virrey Amat, elogios a las pinturas de Ignacio Merino, a los huacos y tejidos incas, a las esculturas de Baltazar Gavilán, entre otros, según observa Luis Alberto Sánchez (1987: 75).

Merece la pena recordar que el proyecto inicial de Valdelomar vinculado a sus novelas cortas, como se alude en múltiples estudios preliminares a su obra, consistía en la creación de un conjunto de tres obras: La ciudad muerta, La ciudad de los tísicos y La ciudad sentimental, aunque la publicación de la tercera nunca se concretó y

\footnotetext{
10 Algunos de los personajes tuberculosos más célebres de la literatura aparecen en $L a$ dama de las camelias de Alejandro Dumas hijo; Crimen y castigo, Los endemoniados o El idiota de Fiódor Dostoievski; o Los miserables de Víctor Hugo; La montaña mágica, de Thomas Mann; o el cuento "La verdad sobre el caso del señor Valdemar”, de Edgar Allan Poe. Valdelomar demuestra no temer al lugar común al elegir dos nombres emblemáticos entre las novelas sobre tísicos: Armando y Margarita, los personajes principales de La dama de las camelias, o al situar la aldea en la sierra, con su clima sabidamente propicio para la recuperación de males respiratorios.
} 
no se conserva un manuscrito ${ }^{11}$. Nunca podremos conocer la temática exacta de la tercera obra sin una explicación del propio autor, pero hay motivos para sostener, por el título y las novelas predecesoras, que habría versado sobre descubrimiento de la génesis de una nueva sensibilidad que cerrara el círculo. De este modo, la primera novela expresaría la muerte de la ciudad colonial; la segunda haría las veces de purgatorio o espacio intermedio en el que las tradiciones interactúan para favorecer el nacimiento de la "ciudad sentimental", que debió haber sido caracterizada en la última entrega. La cantidad de aristas narrativas y personajes que el iqueño debió contemplar alrededor de este último proyecto, más íntimo y definitorio, pudo desbordar y desdoblarse entre sus cuentos, crónicas y discursos posteriores (aunque, a veces, parece cobrar la forma de su aldea entrañable en el puerto de Pisco). Para sustentar mejor esta figuración, veremos cómo se expresa aquel recorrido por las ciudades imaginadas en las novelas que sí vieron la luz.

\subsection{El eterno luto de la ciudad colonial: una perspectiva cristiana}

El pasado adquiere la forma de ruinas que custodian celosas el tiempo detenido de magnificencia en La ciudad muerta, como en una suerte de luto dilatado. Así lo explica el narrador: "Estas ciudades netamente españolas no podían vivir la delictuosa época de la República. Eran como nobles arruinados. [...] Entre esos muros terrosos y caídos, entre esas palideces de polvo, bajo esos techos derruidos se dieron un día las fiestas más espléndidas" (Valdelomar 2014: 46). Como en un cementerio cristiano, los restos deben reposar alejados de la ciudad y de los vivos; por ello, el puerto de "C", donde radica el narrador y el resto de la población, y las ruinas

\footnotetext{
11 Aun así, el nombre dio título a una serie de crónicas publicadas en La Prensa en 1917. Aunque estas carecen de un esfuerzo por forjar una propuesta integral. Entre ellas, se hallan "La dama del violonchelo" o "Las huerfanitas". Como bien menciona MartínezAcacio, las viejas evocaciones, por ejemplo, a la quinta del Virrey Amat en La ciudad de los tísicos, dan lugar aquí a un retrato de la Lima contemporánea y, en algunos casos, a un juicio crítico (2007: 145).
} 
de la ciudad colonial, lugar al que solo llegan los exploradores, aparecen espacialmente separados.

Los elementos religiosos que conforman el espacio siguen la ritualidad y veneración a la muerte como concepto más tradicional dentro del topos europeo y del universo cristiano. Son equiparables, por ejemplo, a los que configuran los ambientes de decadencia construidos por Rodenbach o Azorín, donde la omnipresencia de la religión se percibe como un amplificador del luto o la culpa del protagonista, y es capaz de propiciar una sintonía entre la oscuridad que desprende el personaje y la atmósfera fúnebre de la ciudad (Cuvardic García 2013: 40).

La muerte obra con crueldad frente a los excesos de una "ciudad tan orgullosa que el tiempo ha querido castigar su orgullo como a una mujer coqueta”, que, además, muere en su momento de plenitud y queda sepultada "íntegramente colonial” (Valdelomar 2014: 46). La condena proviene del corazón mismo de la ciudad enterrada, el ahora ruinoso Tribunal de la Santa Inquisición, que domina el espacio y es descrito como la instancia que salvaguarda la historia local, al demostrar, a través de sus "crueldades" un "profundo amor a la Historia y al Pasado" (Valdelomar 2014: 62). Pero la muerte sería una dulce condena en este caso, convertida en un mecanismo de protección frente a la decadencia del paso de los años. Cuando el narrador escribe que "amar el pasado es como alargarnos la vida" (2014: 50), revela que su sentimiento de nostalgia lo induce a congelar el recuerdo y respetar los vestigios con respetuosa distancia. El final prematuro y abrupto de la ciudad colonial —cual tísico que perece en plena juventud- sirve para protegerla de la "contaminación" por convivir con el tiempo culturalmente disímil de la República. Esta intención subyace en la inquietante descripción de la plaza de la Santa Inquisición: "En los restos del edificio había aún santos en los nichos de los muros. La puerta entreabierta y despedazada dejaba entrar rayos de luna y en la serenidad de su secular abandono, las cornisas, las torres, los ornamentos de los capiteles proyectaban sobre el piso sombras que daban miedo" (2014: 62). 
La muerte se vislumbra en el sentido occidental, temida, con guadaña en mano, poderosa ejecutora del fin de la vida de los hombres: "Los golpes fatales sonaban, lejos, pero muy lejos. Entonces no pude más. Tuve miedo y eché a correr con todas mis fuerzas" (Valdelomar 2014: 67). A este respecto, el sentimiento religioso se asocia a la culpa, al castigo y al miedo. Es el sentido cristiano de la muerte como fin de la vida, sin posibilidad de trascendencia ni de huida.

\subsection{La trascendencia de la ciudad colonial: una perspectiva andina}

Mientras que en La ciudad muerta el sentimiento religioso estimula el suspenso en el lector, en La ciudad de los tísicos la muerte y la religión favorecen la aparición de una atmósfera apacible. Incluso, propician la cimentación de una auténtica torre de marfil para las sensibilidades artísticas de los enfermos. Como explica Nouzeilles, en la cultura finisecular, el sanatorio de tuberculosos constituía una "sociedad artificial basada en una comunidad de iguales", que podía representar una intención de autonomía artística, alejada del "materialismo y la vulgaridad” (Nouzeilles 1998: 300). En la novela, las reminiscencias virreinales y los paisajes andinos alimentan la necesidad estética de los espíritus moribundos, refugiados en su ciudad melancólica, con valles abarrotados de flores y palacetes donde celebran fastuosas fiestas. Mientras tanto, la muerte andina cerca y defiende los límites de la ciudad, que desde fuera parece más una cárcel que un refugio: "Voy ahora por el borde de un canal entre cuyos muros el río jura, maldice y se desespera, y suenan las piedras como el rechinar de monstruosas dentaduras, en medio de su prisión de muros de cal y arena" (2014: 89).

Aquella visión protectora y dinámica de la muerte andina marca un nuevo y distinto devenir para la ciudad colonial, porque no se resigna a entender su muerte como un destino trágico, sino que abre una ventana de transcendencia y continuidad:

Entre los incas la muerte no es cesación sino actividad, cambio de lugar; y esa muerte no tiene la guadaña que corta, que mata, que hace verter sangre, sino el tambor que aterra, que señala una hora, que recuerda una cita. Y cita sonriendo, con su graciosa, amable y 
amada sonrisa [...]. Esta apacible sonrisa de la muerte incaica me hace amar a la muerte [...]. La muerte incaica es misteriosamente buena; más que un juez, parece la oficiante de una fiesta fatal (2014: 81) [El énfasis es nuestro].

En contraposición, el narrador expresa que la "muerte cristiana es terrible, cruel y macabra, odiosa y sanguinaria; su guadaña hiere sin piedad y la sonrisa de sus dientes sin boca es irónica y maligna” (2014: 81).

Esta perspectiva, en términos generales, tiene un correlato en el cronista que más defendió las ideas religiosas de los incas, como perfecto estadio previo a la evangelización cristiana, el Inca Garcilaso de la Vega. Iván Rodríguez Chávez advierte la influencia de los Comentarios reales en el acercamiento de Valdelomar al universo andino (2003: 69); y, probablemente, también al crear parte del trasfondo teológico de la novela, que contempla una convivencia entre la vida y la muerte, y construye un escenario caracterizado por el sincretismo religioso. En el "Libro II" de la Primera parte de los Comentarios, el cuzqueño plantea que los incas "no entendían que la otra vida era espiritual, sino corporal, como esta misma” ([1609] 1970, II, VII: $88)^{12}$, con lo que no cabía la oposición radical vida/muerte occidental. Además, que "tuvieron asimismo los Incas la resurrección universal, no para gloria ni pena, sino para la misma vida temporal, que no levantaron el entendimiento a más que esta vida presente” ([1609] 1970, II, VII: 88). La antropología moderna resume los postulados con la misma sencillez depurada con que Valdelomar los encaja en su narrativa: en las comunidades andinas morir "no constituye una tragedia [...], más bien, la muerte es como una conclusión, cumplimiento y culminación de una etapa de la vida [...]. Nunca es el final o la terminación del ser; es continuidad del ser dentro de la totalidad existencial y universal” (Sánchez Garrafa 2015: 68).

Valdelomar rescatará esta noción de temporalidad para insuflarle nueva vida. La muerte aparece como fenómeno capaz de coexistir

12 Indico el número del libro y del capítulo en números romanos respectivamente y la página en arábigos (ver bibliografía). 
con la vida en La ciudad de los tísicos, y el tiempo oscila entre el paralelismo o la circularidad, hasta dejar de ser una sucesión lineal. Así lo expresa la tísica Rosalinda cuando dice: "Yo veo la vida desde un punto inaccesible para todo. Estoy en una distinta vida, donde el tiempo no medita. Sentí que hubo un momento en que terminaban las cosas y yo seguía viviendo...” (2014: 99-100).

No es casual que Valdelomar buscara la exaltación de esta visión prehispánica de la vida a través de la figura romanceada del tísico. Como explica Sontag, "la tuberculosis es una enfermedad del tiempo; acelera la vida, la pone de relieve, la espiritualiza” (2003: 27). De hecho, citando a Charles Dickens, describe esta afección como una “'aterradora enfermedad' que 'refina' la muerte quintándole sus aspectos groseros" en que la "batalla entre el alma y el cuerpo es tan gradual, tranquila y solemne, y el resultado es tan seguro, que día a día [...] la parte mortal se consume y se marchita, de modo que el espíritu se aligera y se llena de esperanzas por su peso menguante" (Sontag 2003: 30). Esta gradualidad deseada y esperanzadora, aterriza mucho más suavemente en la idea de la trascendencia andina, y sirve al autor para tomar una posición sobre su propia concepción de la lenta agonía del pasado virreinal.

4.3. Las dos muertes dialogan: una propuesta de lectura tipológica

Los personajes de La ciudad de los tísicos conviven plácidamente con la muerte y habitan el espacio de una ciudad paralela; por su lado, en La ciudad muerta, el protagonista desea alejarse a toda costa de aquel reino del misterio que invita a unos, con su atractiva oscuridad, y atormenta a otros, los que rehúyen a la locura y se aferran al presente de los vivos. En ese sentido, apreciamos un giro discursivo que va desde la negación y el temor cristiano en la primera novela hacia la celebración andina de la muerte en la segunda. No obstante, este no es abrupto ni excluyente, sino que se anticipa desde la primera novela de la trilogía inconclusa.

En principio, luego de analizar los perfiles del narrador-protagonista de La ciudad muerta y los dos personajes a los que conduce (o piden ser conducidos) hacia su lecho de muerte, salta a la vista la 
semejanza de estos con la caracterización del personaje tísico por excelencia: un ser de elevado sentido artístico y actitud irreverente frente a la muerte y a cualquier dogmatismo. Dado que las novelas se escribieron casi a la vez y que la temática es más que afín, es bastante probable que Valdelomar perfilara a sus personajes tuberculosos desde aquel primer texto y reforzara, con ello, un sistema dialógico. Así se percibe en la sección "Locaciones cerebrales" de La ciudad muerta, donde la atracción tanática se expresa a través de una analogía sobre el encanto de la oscuridad. Como explica el narrador, al bajar al subsuelo, fácil metáfora del encuentro con la muerte, el sistema de relaciones cerebrales pierde funcionalidad, debido al corte abrupto de la luz; esto debería potenciar otros sentidos de orientación, como el olfato; pero en este subsuelo, con sus olores particulares y su profundidad, el sentido de supervivencia se anula por completo:

Al entrar usted al subterráneo, trabaja poderosamente a consecuencia de los olores especialísimos de ese lugar. Estas vibraciones de la pituitaria se reflejan en su lóbulo correspondiente y presionan al lóbulo inerte de la vista. Hay pues ya dos fuerzas activas actuando sobre una materia en reposo, que por esta influencia pierde su virtud [...]. Entonces a la necesidad natural de la luz sucede, por oposición, la necesidad de la obscuridad (2014: 60).

Nos encontramos frente a una dicotomía entre el protagonista racional y los personajes que se inmolan atraídos por lo insondable. Aquel es representado como un hombre mental y físicamente sano, tanto que sería, en palabras de Nouzeilles, casi un "inválido de imaginación” (1998: 308) ${ }^{13}$. Además, es poseedor de un pragmatismo científico y de una flaqueza de carácter típica del héroe finisecular. En este caso, su visión pseudorracionalista le permite justificar sus temores sobre lo oculto (Martínez-Acacio 2007: 125). Los otros dos son personajes curiosos y dispuestos a explorar la ciudad enterrada.

13 Nouzeilles emplea la expresión en su análisis de La ciudad de los tísicos para explicar la incapacidad del protagonista para ver lo que Abel percibía como "artístico" dentro de la realidad, porque gozar de buena salud le impide "crearse un puente entre las dos ciudades" (1998: 308). 
El primero en bajar al subsuelo de la ciudad colonial acompañado por el narrador es Rosso, un alma sensible y artística, pintor de la nueva escuela, quien llegó a la ciudad en busca de una pintura de Murillo que debía ser rescatada de las ruinas. Rosso emplea elementos propios del cristianismo, pero desde su propia perspectiva, guiada más por la estética, la curiosidad y la superstición antes que por una devoción ortodoxa. Por ejemplo, tiene la firme creencia de que, si se separa de un Cristo de palo santo que carga consigo, algo nefasto le ocurrirá (2014: 54). Su actitud caprichosa es afín a la personalidad infantil que adopta el tísico literario, quien, como explica el médico Leopoldo Cortejoso, retorna a la infancia y a la naturaleza más esencial, caracterizada por "la inconstancia, la negligencia, la avidez de simpatía y amor, juntamente con la facilidad que el enfermo tiene para convertirse en esclavo de sus caprichos" (1943: 25).

Por otro lado, cuando se representa a Henri, el segundo en aventurarse al subsuelo, este se muestra intrigado por los estímulos de la ciudad y con los sentidos exaltados por un estado de enajenación. En la descripción de su gesto representativo de artista, hay un parecido importante con las reacciones de la enigmática dama de negro que enloquece al oler el perfume de flores de lys en la primera parte de La ciudad de los tísicos - y que, según se revela al final, sería Magdalena de Liniers-: “Henri D’Herauville tenía el gesto de lo insondable [...]. Llevaba el gesto en la boca. Una boca de misterios, unas comisuras que intrigaban. Sus movimientos eran armónicos. Su nariz lanzada hacia arriba agitaba los cartílagos vibrantes y husmeaba como los perros que buscan algo que no han encontrado todavía" (2014: 43). En similar rapto sensorial, en La ciudad de los tísicos, la mujer, que se ubica también en un punto intermedio entre el mundo de los tuberculosos y el de los vivos, "agita las ventanas rápidamente y aspira como un pajarillo en la campana neumática [...]. Mi perfume la embriagaba, la dominaba, la atraía” (2014: 73).

Por último, mientras el narrador de La ciudad muerta aparece aterrado y arrepentido de cada paso que da hacia la entrada del subterráneo, Henri repite versos del poeta Albert Samain desde un 
estado casi hipnótico, con lo cual se revela un vínculo a la ciudad en ruinas: "cuya alma fatigada por los siglos le responde/ en esta laxitud indecible de la hora” (2014: 62). El personaje hace referencia una y otra vez a la noche negra que anticipa el desenlace. Se conduce como si su alma agonizara desde antes de esa noche, como un tísico que no teme ser guiado hacia la oscuridad y sin posibilidad de redención.

Otro punto de diálogo entre las novelas es la apelación al universo cristiano. En La ciudad de los tísicos, los elementos cristianos siguen siendo ornamento melancólico de la ciudad colonial. Aparecen en perfecta comunión con la necesidad de reposo de los enfermos y su alto grado de espiritualidad, pero desprovistos de la severidad de su novela anterior. El velorio de la pálida y frágil sor Luisa de la Purificación, quien emula a santa Rosa de Lima en belleza, palidez y fragilidad, se percibe como una ceremonia deleitosa para los asistentes y que tampoco representa el fin de una vida. De hecho, es la prolongación de una muerte que ya había empezado a producirse: "tenía otro aspecto de cadáver animado y a mí me hacía el efecto de una persona que salía, caminaba y rezaba siempre, pero que había muerto hacía mucho tiempo" (2014: 117). De igual modo, se describe el sueño de Rosalinda la Triste, dentro de una gruta, como una “virgencita musgosa” (2014: 98) a la que podrían dirigírsele pías oraciones.

La tuberculosis había sido interpretada como un camino de santidad en el imaginario decimonónico, por la creencia de que aligeraba el espíritu y desvinculaba al hombre del mundo terrenal. Según detalla Cortejoso, "el amor, la bondad, la castidad, la exaltación de la afectividad, la compasión, el deseo de martirio, llevan al tuberculoso hacia la santidad [...]. Sobre todo cuando se acerca el final, el enfermo pone los ojos en Dios, la fe le transforma totalmente, piensa que el dolor le traerá el premio de la ventura ultraterrena” (1943: 31). Los tísicos sufren la enfermedad en vida, pero como un camino hacia la elevación plena de sus espíritus. Las fuerzas espirituales, a la vez que consumen el cuerpo en la fiebre tísica, aligeran el alma, depurándola, "como si en la enfermedad se fuese quemando 
una carga perjudicial de errores y aciertos" (Cortejoso 1943: 232). La apropiación de los elementos cristianos en La ciudad de los tísicos está desvinculada de la culpa o el miedo de la novela anterior. Los tísicos armonizan dos tradiciones y procesan la muerte sin culpa: la fe cristiana es decorado y forma; la religiosidad andina, fundamento de una existencia espiritual que concilia los planos vida/muerte.

5. El verdadero simbolismo de la ciudad muerta: una nueva lectura del pasado nacional

Aunque no es la faceta más reconocida de Valdelomar, su sentimiento patriótico y activa participación dentro del discurso identitario de su tiempo fue notable. No se trata de proponer lecturas ideológicas por añadir valor a dos obras relegadas, sino de respetar una poética que combina vida pública y ficción por propia convicción del autor, que se construye a sí mismo como escritor militante y participa de una coyuntura en que "el narrador/cronista/hermeneuta reproduce un debate por la constitución de la tradición nacional” (Álvarez Chacón 2003: 76). Asimismo, la novela modernista es un formato con trasfondo ideológico en sí mismo, pues, como plantea Aníbal González, tiene por característica la necesidad del artista de definir su posición frente a la sociedad (Álvarez Chacón 2003: 76). A diferencia de un cuento o de un poema, retomando las ideas de Mijail Bajtín, el esteticismo en una novela no se manifiesta en su estructura formal, sino en la ideología del personaje esteta caracterizado, que aparece preocupado por el futuro de su propia visión artística y sus postulados (Álvarez Chacón 2003: 73).

Pese a todo ello, la crítica tradicional se ha mostrado indecisa o escéptica al abordar el interés político que Valdelomar manifiesta en su obra ficcional. M’Bare N'Gom, uno de sus más severos lectores, lo acusa de articular un discurso nacionalista "monolítico y excluyente” (2004: 112). Mónica Bernabé, por otro lado, hace frente a la cuestión con su propuesta más conciliatoria de encajar vida pública y obra a través del concepto de "nomadismo" (2003), con lo cual invita a revisitar los matices políticos en la narrativa valdelomariana, 
pero insiste en un análisis por fases. Según explica, la incorporación al partido político de Guillermo Billinghurst en 1912 y su participación en la delegación oficial enviada a Roma en 1913 representarían un hito en el pensamiento del escritor, que, a partir de entonces, logra dirigir su mirada "hacia fuera" y alcanzar una voz literaria "verdadera", de manera que las dos novelas cortas pasan a formar parte de la "fase artificiosa":

desde el momento en que "el pueblo" entra a formar parte como referencia en sus relatos, la crítica vislumbra al "otro", al "verdadero" Valdelomar, el que se oculta detrás de la "artificiosidad” y de los circunstanciales disfraces. Cuando sus relatos abandonan el paisaje decadente que decora La ciudad de los tísicos y La ciudad muerta e ingresa al más reconocible de la aldea encantada, Valdelomar es habilitado, o se habilita, como escritor nacional (Bernabé 2003: 45).

Al leer su obra desde aquella división entre el dandi moderno y el aldeano sentimental, estaríamos yendo contra la propuesta del escritor de construir una literatura nacional capaz de abarcar conceptos y estéticas en apariencia inconciliables. De hecho, como autor “eslabón” entre el modernismo y las vanguardias, las contradicciones y la convergencia de enfoques más o menos originales son intrínsecas a su poética, de modo que deben asumirse con naturalidad. Más que una "estrategia de representación”, como plantea Bernabé (2003: 43), podemos ver en el dandismo de Valdelomar una expresión exacerbada de su espíritu crítico y rebelde, frente a un proceso cultural complejo y de cambios dramáticos (McEvoy 1999: 269-270), no la negación de una voz auténtica ${ }^{14}$. En todo caso, el viaje a Roma significó la posibilidad de reflexionar sobre el país desde fuera, lejos de la

\footnotetext{
14 Recientemente, Marie Elise Escalante ha retomado el interés de Bernabé por la perspectiva política en la obra de Valdelomar y lo ha llevado más lejos al estudiar la condición dual de escritor modernista, y sujeto migrante en los cuentos criollos y sus dos novelas cortas, para contrastarla con los discursos patrióticos. Una parte de su trabajo se centra en demostrar la preocupación por desestabilizar las representaciones oficiales de la nación y el centralismo político (2017: 40). En este trabajo se amplía el horizonte de análisis hacia la aceptación del doble posicionamiento en el autor; es decir, para la interpretación de un corpus híbrido.
} 
angustia de un centro convulso y cambiante y del escrutinio de sus coetáneos; ello explicaría que textos tan distintos como las crónicas de Roma, cargadas de decadentismo, se escribieran a la par de la prosa tierna y sencilla de su cuento más célebre, "El caballero Carmelo".

Tras estas aclaraciones, sabemos que en el modernismo liderado por Valdelomar se halla una intención que excede por mucho la imitación de modelos. En sus novelas, queda reflejada la dolorosa interacción entre el futuro nacional y el pasado histórico, desde la consciencia de que la consolidación de una identidad nacional debe basarse en la convivencia de los elementos que conforman el conjunto híbrido, a veces contradictorio. El escritor peruano pretendía diferenciarse de la generación del novecientos para proponer una literatura que se apartara de la "Arcadia colonial”, así como de la glorificación e idealización incaica más paternalista. Más que apolíticos, sus primeros textos, entre los que destacan las dos novelas, expresan un temprano deseo de renunciar a las visiones radicales para fundar un panorama integrador.

\subsection{Un arte nuevo desde las ruinas}

La sensibilidad valdelomariana perseguía la libertad de expresión artística combinando elementos de manera regeneradora y no selectiva. Según expresa el escritor en uno de sus discursos sobre la literatura peruana, su propuesta artística se basa en una fórmula sencilla: el arte es el producto de la naturaleza y el espíritu. Con una lógica que desprende tanta lucidez como ironía, propone que la renovación artística debería surgir de la mezcla entre naturaleza moderna y espíritu moderno: "Si convenimos en que hay aquí dos elementos que han tomado hoy otro valor, como son la Naturaleza y el espíritu humano, tendremos que en la anterior igualdad había que poner Naturaleza moderna y Alma moderna, en vez de naturaleza y Alma y, para conservar la proporción, Arte moderno" (Valdelomar 2001, IV: 224). El principal obstáculo del supuesto arte nuevo de principios del siglo XX es que bebía de un espíritu añejo y de una naturaleza instalada en antiguas glorias, con lo cual se hacía inviable el ideal de "innovación sensata, mejoramiento lógico, 
adelanto apreciable" (Valdelomar 2001, IV: 225); es decir, el ideal de actualización de un arte que no fuera remedo de sus herencias.

Colónida, revista que funda y dirige Valdelomar en 1916, y que daría luego lugar al movimiento literario del mismo nombre, persigue la libertad del arte moderno desde un formato integrador y tangible, aunque el resultado tienda más al caos que a una propuesta sistemática, como se le ha criticado ${ }^{15}$. Pese a la agresiva recepción que tuvo en su tiempo, con sus únicos cuatro números significó una verdadera revolución estética, a través de géneros tan diversos como la crónica, la caricatura, el relato breve o la poesía. Como afirman José Miguel Oviedo y Mirko Lauer, Colónida "inaugura una conciencia cultural" y defiende un "cosmopolitismo que devolviese al país su autonomía cultural” (2004: 102). El propio nombre de la revista remite a una "ambición descubridora y pionera [...]. Era una secuela de la obra de Colón, un pie en un nuevo mundo: el de la nueva literatura” (Sánchez 1981: 7). Debido a la breve vida del autor peruano, puede que solo le faltara tiempo para liderar un proyecto más sólido o escribir la obra que satisficiera sus ímpetus de sincretismo innovador, pero es innegable que cada uno de los esfuerzos, en su conjunto, lograron desmontar algo de lo que venía siendo una literatura elitista y sin juego.

Desde la perspectiva de Valdelomar, quien sí habría alcanzado en el pasado un arte genuino para el Perú —y a quien deseaba emular en aquella empresa- era Baltazar Gavilán, al cual evoca en La ciudad de los tísicos. El escultor peruano del siglo XVIII sería hasta entonces el único artista con la destreza de conciliar y recrear las herencias pre hispánica y española desde el concepto mismo de la muerte. Así lo establece el iqueño en otro de sus discursos: "Si entre nosotros hubiera aparecido un temperamento capaz de recoger la herencia artística de Baltazar Gavilán, el más intenso y original de nuestros artistas, tal vez tendríamos un arte propio. Pero aquel indio cuyo espíritu inquieto

\footnotetext{
15 Mariátegui consideraba que, debido a su carácter "demasiado heteróclito y anárquico", el movimiento literario al que da lugar, "no pudo condensarse en una tendencia ni concretarse en una fórmula” (1982: 253-254). Eva María Valero defiende su relevancia sobre la base de su "renovación de una actitud, libre y espontánea" y de la reivindicación que hace de un pensamiento anti centralista (2007: 80).
} 
y atormentado diera forma a la trágica y pavorosa escultura de La Muerte, fue una rara flor de la Colonia” (2001, IV: 98).

El breve fragmento vuelve, una vez más, sobre la preocupación del escritor por hallar la receta del arte conciliatorio, pero ya reconoce a la muerte como concepto artístico cauterizador. Y esta potencialidad cobra aún mayor fuerza a través del universo andino, donde "la muerte induce el reconocimiento social de permanecer unidos, de reconocerse a sí mismos a través de los ancestros comunes, y de generar un mecanismo especial que cohesione más a los individuos. La muerte trae unión y memoria, no separación ni olvido” (Sánchez Garrafa 2015: 69).

5.2. "No busque nunca en las viejas ciudades": hacia la edificación de una ciudad literaria

El vínculo más fuerte entre el proyecto de patria literaria que esbozó Valdelomar a lo largo de su corta vida y las dos novelas que nos conciernen aparece concentrado en los finales de ambas. La misma premisa fatalista reposa en las advertencias de dos de sus personajes para revelar que ambos han adquirido una lección fundamental tras su acercamiento a la muerte. En La ciudad muerta, el protagonista, ya abatido por los desenlaces "trágicos" de los dos hombres a los que condujo hacia los subterráneos, advierte a su antigua prometida sobre los devastadores efectos para la cordura de fijar la atención sobre las ciudades enterradas: "Oh, Francinette, desconfíe usted de las noches de luna, no busque nunca las ciudades viejas. Ambas cosas conducen al misterio, a la locura, al crimen, a la fatalidad" (2014: 68). En concordancia, en La ciudad de los tísicos, la enigmática Magdalena de Liniers, aconseja al narrador, quien se confiesa "enamorado de lo desconocido” (2014: 123): “¡No romper el encanto de lo misterioso; no hacer reales nuestros deseos; no conocer aquello que se nos presenta esfumado, porque la realidad habrá desvanecido lo extraño y el ideal se habrá perdido para siempre!” (2014: 123). Como escribe Edmundo Bendezú, aquellas palabras de Magdalena "encierran el secreto de la estética modernista, siempre renuente a cualquier vano intento de conocer la realidad o representarla” 
(2003: 132). Pero también insinúan una clave de apreciación de la belleza colonial del país.

Como buen seguidor de su propia filosofía, Valdelomar dispone para su escritura del tiempo perdido de la Colonia, aunque sin caer bajo el hechizo del pasado. Tampoco teme sacudir el polvo sobre los vestigios para ubicar viejos valores, personajes y sensibilidades como insumo para la creatividad de su ser melancólico. Así, ni en su modo clásico ni en la adaptación peruana se pretende repetir un tiempo pasado por medio del topos, sino todo lo contrario: el objetivo es preservar la ilusión inspiradora por otra época para crear un producto vigente, paralelo al presente que se rechaza. Valdelomar no propone, de esa manera, habitar el pasado desde una continuidad neocolonial o eternizar la celebración incaica, tampoco la miedosa distancia; sino la posibilidad del sincretismo literario.

Un axioma se desprende al vincular las dos sentencias de las novelas: la literatura ya no debía seguir vigilando obsesiva e infructuosamente las ruinas del pasado nacional, pre hispánico o colonial, porque ese camino conduce a la fatalidad y a la pérdida del misterio, o porque simplemente es un ejercicio inútil. La literatura debía ser capaz de renovar sus viejos temas sin temor a la "profanación” modernizadora para crear un arte original y representativo. Julio Ramón Ribeyro, varias décadas después, demostraría haber asimilado una lección similar, desde una búsqueda más subjetiva, al escribir en Prosas Apátridas: "Mi error ha consistido en haber querido observar la entraña de las cosas, olvidando el precepto de Joubert: 'Cuídate de husmear bajo los cimientos'. Como el niño con el juguete que rompe, no descubro bajo la forma admirable más que el vil mecanismo. Y al mismo tiempo que descompongo el objeto destruyo la ilusión" (1986: 126) ${ }^{16}$.

\footnotetext{
16 De hecho, Valero ha estudiado los vínculos entre el topos clásico de la "ciudad muerta” en Ribeyro en su artículo "El trastorno de los sentidos: emergencias de la ciudad muerta en la obra de Julio Ramón Ribeyro” (2005).
} 


\section{Conclusiones}

El artículo propone un acercamiento las dos novelas cortas de Abraham Valdelomar, La ciudad muerta y La ciudad de los tísicos, en estrecha ligazón al proyecto de gestación de una fórmula nacional para un arte nuevo que lo acompañó toda su vida. Por medio de la adaptación del topos finisecular de la "ciudad muerta" y de los rasgos y personajes propios de la novela modernista, invita a su lector coetáneo a superar la muerte de la ciudad colonial, sin recurrir a anclajes ideológicos o situarse dentro de los sectarismos que dominaban la escena intelectual de principios del siglo XX. Para ello, el escritor habría trazado una ruta de duelo a través de sus novelas, que inicia con el solemne luto cristiano frente a los restos de una bella ciudad enterrada; posteriormente, busca el consuelo que ofrece la percepción andina de la muerte y la posibilidad de una transcendencia temporal; $y$, por último, abre paso a la experimentación ideológica y formal para la construcción de una nueva ciudad literaria.

En esa línea, La ciudad muerta simboliza el dolor, el miedo y la negación por dejar atrás un periodo de esplendor nacional; mientras que La ciudad de los tísicos, la aceptación y la feliz remembranza dentro de un presente todavía enfermo de nostalgia, consciente de necesitar una autonomía artística y ubicado en una suerte de limbo histórico. Tras dibujar los dos escenarios como una proyección de la decadencia espiritual del hombre, la consagración de un nuevo arte permanece para Valdelomar como la promesa de una estética vinculante y que presuma de sus múltiples raíces. No vamos a cuestionar aquí si la alcanzó o no con su propia literatura ecléctica, compleja y hasta contradictoria. Sin embargo, un análisis comparado de sus dos novelas sí nos permite sacar en limpio que el camino hacia la estética nacional no reside en la incorporación o adopción forzada de vestigios históricos, incaicos o coloniales, por asumir, como dicta el viejo refrán, que todo tiempo pasado fue mejor. La clave valdelomariana estaría en remover las ruinas y "profanar" la historia del país al más vivo antojo modernizador. 


\section{Referencias bibliográficas}

Álvarez Chacón, Edgar

2003 "Notas en torno a La ciudad de los tísicos y el modernismo peruano". En Valdelomar. Memoria y leyenda. Ed., pról. y notas, Jesús Cabel. Lima: Instituto Nacional de Cultura, 71-78.

BASADRE, Jorge

1968 Historia de la República del Perú (1822-1933). Vol. XI. Lima: Editorial universitaria.

BENDEZú, Edmundo

2003

"Abraham Valdelomar". En Valdelomar. Memoria y leyenda. Ed., pról. y notas, Jesús Cabel. Lima: Instituto Nacional de Cultura, 121-133.

BERnABÉ, Mónica

2003 "Dandismo y rebeldía en el Perú: el caso de Abraham Valdelomar". Iberoamericana III. 11, 41-63. Consultado: 15 de mayo de 2018. <https://journals.iai.spkberlin.de/index.php/ iberoamericana/article/viewFile/615/299>.

CAnsinos-Assens, Rafael

1925 La nueva literatura II. Las escuelas. Madrid: Editorial Páez.

Castro y Oyanguren, Enrique

2003 "Elogio de Abraham Valdelomar". En Valdelomar. Memoria y leyenda. Ed., pról. y notas, Jesús Cabel. Lima: San Marcos, 17-27.

Cornejo Polar, Antonio

1989 La formación de la tradición literaria en el Perú. Lima: Centro de Estudios y Publicaciones.

Cortejoso, Leopoldo

1943 El dolor en la vida y en el Arte. Ensayos médico biográficos sobre tuberculosos célebres. Ed., Joaquín Gil. Barcelona: Iberia.

Cuvardic García, Dorde

2013 "El topos simbolista de la ciudad muerta en la tradición literaria europea y española”. Filología y Lingüística. 39, 2, 27-50. Consultado: 23 de febrero de 2018. https://doi.org/10.15517/ rfl.v39i2.15011 
Escalante, Marie E.

2017 "Abraham Valdelomar: entre cosmopolitismo y provincianismo”. En Migración y frontera. Experiencias culturales en la literatura peruana del siglo XX. Ed., Javier García Liendo. Madrid: Iberoamericana, 39-54.

Friedman, David

1990 The Symbolist Dead City. A Landscape of Poesis. Nueva York y Londres: Garland Publishing.

García PÉrez, Rafael

2008 "Interpretaciones del tópico de la ciudad muerta en la poesía española y francesa”. Cédille. Revista de Estudios Franceses. 4, 119-130. Consultado: 12 de febrero de 2018. https://doi. org/10.21071/ced.v4i.5383

Garcilaso de la Vega, Inca

[1609] 1970 Comentarios reales de los Incas. Vol. 1. Lima: Editorial Universo.

Lozano, Miguel Á.

$2000 \quad$ Imágenes del pesimismo: literatura y arte en España 18981830. Alicante: Universidad de Alicante.

Mariátegui, José C.

$1982 \quad$ Siete ensayos de interpretación de la realidad peruana. Lima: Biblioteca Amauta.

Martínez-Acacio, María E.

2007 Relectura de la narrativa de Abraham Valdelomar en el proceso de formación de la literatura peruana. Tesis doctoral. España: Universidad de Alicante. Consultado: 28 de octubre de 2019. <https://rua.ua.es/dspace/bitstream/10045/87687/1/ tesis_maria_elena_martinez_acacio_alonso.pdf>

McEvor, Carmen

1999 "Entre la nostalgia y el escándalo: Abraham Valdelomar y la construcción de una sensibilidad moderna en las postrimerías de la 'República Aristocrática'. Forjando la nación”. Ensayos sobre historia republicana. Lima: Pontificia Universidad Católica del Perú, 247-313. 
N'Gom, M'Bare

2004 "Raza e identidad nacional en Valdelomar". En Textos marginados sobre Abraham Valdelomar. Comp., César Ángeles. Lima: Ediciones Alpamayo, 108-117.

Nouzeilles, Gabriela

1998 "La ciudad de los tísicos: tuberculosis y autonomía". Anales de la literatura española contemporánea. 23, 1/2, 295-313.

Oviedo, José Miguel y Mirko Lauer

2004 "Colónida: Abraham Valdelomar (1888-1919)". En Textos marginados de Abrabam Valdelomar. Comp., César Ángeles. Lima: Ediciones Alpamayo, 102-107.

Palma, Ricardo

2007 Tradiciones peruanas. Alicante: Biblioteca Virtual Miguel de Cervantes. Consultado: 9 de junio de 2018. <http://www. cervantesvirtual.com/obra-visor/tradiciones-peruanasquinta-serie- $0 / \mathrm{html} />$

RibeYro, Julio R.

1986 Prosas apátridas. Barcelona: Tusquets.

Rodenbach, Georges

2011 Brujas la muerta. Madrid: Vaso roto ediciones.

Rodríguez Chávez, Iván

2003 "El tema incaico en la narrativa de Valdelomar". En Valdelomar. Memoria y leyenda. Ed., Jesús Cabel. Lima: Instituto Nacional de Cultura, 68-70.

SÁNCHEZ GARRAFA, Rodolfo

2015 "Después de la muerte en el mundo andino. Una aproximación antropológica”. Cultura y Religión. IX, 1, 64-81. Consultado: 11 de junio de 2018. <http://132.248.9.34/hevila/Culturayreligion/2015/vol9/no1/4.pdf>

SÁNCHEZ, Luis A.

1981 "Prólogo”. Colónida. Lima: Ediciones Copé, 7-11.

1987 Valdelomar o la "Belle époque”. Lima: Impropesa.

SANTOS, Susana

2015 La novela peruana en la ciudad de Lima (1890-1940). Tesis doctoral. Universidad de Buenos Aires. Consultado: 30 
de octubre de 2019. <http://repositorio.filo.uba.ar/bitstream/handle/filodigital/3008/uba_ffyl_t_2015_89903. pdf? sequence $=1 \&$ isAllowed $=y>$

SONTAG, Susan

2003 La enfermedad y sus metáforas. Madrid: Suma de letras.

VALDELOMAR, Abraham

2001 Obras completas. Vol. I y IV. Lima: Petroperú.

2014 Cuentos reunidos. Ed., y notas, Carlos Garayar. Lima: Peisa.

Valero, Eva M.

2005 "El trastorno de los sentidos: emergencias de la ciudad muerta en la obra de Julio Ramón Ribeyro". La literatura hispanoamericana con los cinco sentidos. $V$ Congreso internacional de la AEELH (2005), 705-712. Consultado: 11 de enero de 2018. $<$ https://ruc.udc.es/dspace/handle/2183/11419>

2007 "El grupo Colónida y la 'herejía antinovecentista". Arrabal. 5, 6, 77-86. Consultado: 15 de setiembre de 2018. <https://www.raco.cat/index.php/Arrabal/article/ view/140510/192082>

Recepción: 28/01/2018

Aceptación: 14/10/2019 